
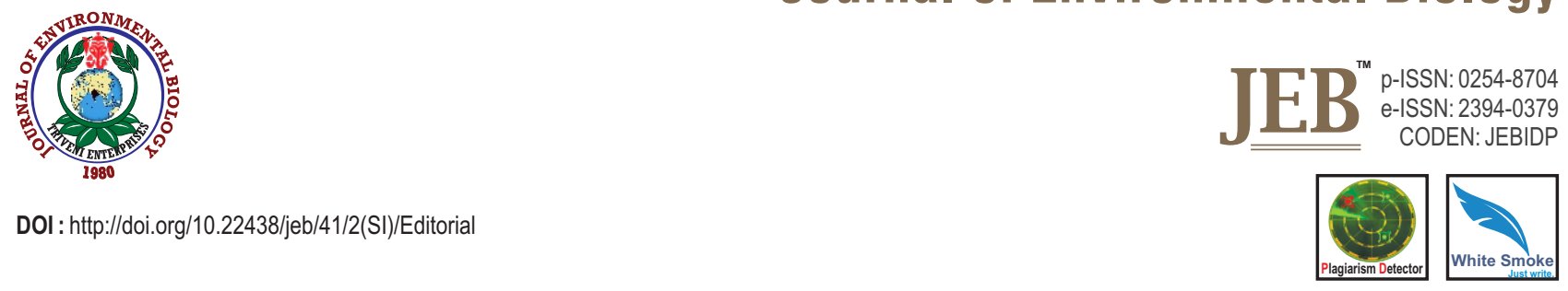

DOI : http://doi.org/10.22438/jeb/41/2(SI)/Editorial

\title{
Environment, Biodiversity, Geography
}

The editors have been deeply involved in the biodiversity studies both geographically as well as at species level, and they have been working on the topics of ecology and biogeography for the last few decades. This special issue deals with our mother earth which is embedded with a wonderful diversity of ecosystems with bees, birds and others pollinating three quarters of major crops on our globe, and all are interdependent, thereby sustaining the whole planet. There are nearly 2 million different species and millions are awaiting their discovery. Biodiversity includes all from tall trees to small single-celled organisms impossible to see with naked eye. These can be measured by counting their numbers in a particular area. Some of the habitats are rich in endemics. Some areas are designated as biodiversity hotspots and their preservation is a must. The Special issue aims to make some contribution in this direction. Biodiversity also means ecosystems and communities of living beings together with their surroundings. We can also look at our biodiversity as genetic diversity because genes are the basic units of biological information. In fact, all living beings are interconnected and depend on each another like beads of a chain, the forests are home to animals, latter eat plants which need healthy soil to live, but fungi act as decomposers thereby helping in the production of fertile soils. If our biodiversity is lost all these connections will break, harming all those living in an ecosystem. Our ecosystems are resistant and stronger simply because of biodiversity. It is important for humans by giving off oxygen, providing food, shade, material support, medicines, and fiber for clothing and paper. Plant roots prevent flooding and parts of biodiversity keep soil fertile and water clean but if it decreases these systems break down quickly. As discussed in this issue, successful agriculture and tourism too depends on biodiversity. Any destruction in this connection will have an immediate impact on the economy of locals in the vicinity. Unfortunately, thousands of species become extinct, or die out entirely, before we learn about their uses. We are losing these species hundreds times were than the natural rate, due to global climate change and destruction of natural habitats, pollution and overhunting the lead to a drop in biodiversity as discussed by several authors in this special issue.

Geographically speaking different regions of the earth receive different amounts of sunlight which effects the length of warm, cold, wet, and dry seasons together with temperature, humidity, and other environmental factors, because of the curvature of the earth as well earth's inclination on its axis relative to the sun. This curvature and rotation are also responsible for our hydrological cycle on earth leading to clear-cut differences in the distribution of rain and snow on our globe as well as varying environmental conditions together with differences in vegetation types.

Deforestation is a significant problem in today's world with primary, old-growth forests cut by humans for fuel, as well as building construction, and other household stuff. This degradation due to non-sustainable deforestation goes against the sustainability of our environment. Drought and salinity are also posing great threat because climatic conditions vary across different latitudes, the species diversity also varies to a great extent. Aquatic ecosystems like terrestrial ones support large number of species, particularly fish and amphibians. The base of the food chain that supports our life begins with life promoting bacterias. These decomposers as well as chemosynthetic bacteria provide a rich food source for a multitude of fishes unique to our oceans. We also have keystone species possessing low functional redundancy, and any organism, from plants to fungi, may be a keystone specie. These organisms help us to define the entire ecosystem, and without these our ecosystems would be different or cease to exist altogether; their disappearance will mean no other species can fill their ecological niche, the ecosystem will change radically and new and possibly invasive species will enter the system allowing to populate the habitat. several other categories of living organisms are crucial for ecosystem survival such as umbrella species, their value is tied to their geographical range, are migratory, have large habitat needs, and their range may include different habitat types. The foundation species like corals too play a major role in creating or maintaining a habitat. We also have ecosystem engineers contributing to the physical geography of their habitat, modifying, creating, and maintaining habitats, some being autogenic, some allogenic, some invasive, some indicators, and some as flagship species.

This special issue covers original articles on the topics related to ecology, biodiversity, ecogeography, climate change, toxicology, biotechnology and landscape planning in 32 manuscripts by a myriad of researchers from different countries. 
First manuscript presents the findings on Epigaea gaultherioides - a genetic heritage, with discussions on better understanding of ecological requirements of this relict taxon for its possible future successful conservation programs.

Avian diversity from the Mangrove forests of Malaysia is the second paper which enlightens the diversity analysis which is more diverse than the other river systems. The occurrence of mudflats, shallow water, richness of food and dense vegetation are considered here as important factors affecting the richness and diversity of water birds as well as terrestrial or open country birds in the mangroves facing great disturbance currently.

Third paper analyses the areas suitable for ecotourism using GIS. It has stressed the fact that fairy chimneys together with surrounding high mountains together with rocky areas and valley plains, areas near the rivers and stream waterbeds and forests possess important potential for ecotourism.

Paper four covers studies on the yield response of Limonium sinuatum cultivars under salinity stress. It presents data on the results of analysis of salinity levels using saline-resistant ornamental plants in landscape designs rather than cut flowers.

Fifth paper presents data on the distribution of metals in the soils contaminated by gold and copper mining. The authors have found that atomic mass of elements can influence their movement in the air. A formula for relative distribution of elements has been developed depicting the possibility to estimate the contamination degree of polluted soils.

Studies on the ecological impacts of a city forest and level of public awareness for recreational use is presented in paper number six, which emphasizes the role of urban forests in the economy, ecology, aesthetics and social values of the cities.

Paper seven presents the impacts of quarries on the Kyrenia mountains in Cyprus, stressing the lack of legislation on the improvement of quarries, which needs to be adopted to prevent the horrible structural deformation and environmental degradation.

The present species composition and diversity in dry temperate forest ecosystem as an important habitat for wildlife fauna species is the subject of paper eight. This study demonstrates that plant cover structure and composition of dry-temperate forest is the most prominent factor forming a wide array of different habitats to attract the higher diversity of fauna.

In paper nine, hydrodynamic zones of the fissure-karst waters of Zemo Imereti Plateau in the Republic of Georgia has been studied and a scheme of hydrodynamic zones drawn revealing the fact that these zones undergo a constant change in the background of ascending tectonic movements. Paper ten discusses the NDVI indicated changes in vegetation and their relations to climatic comfort factors. Authors stress that artificial neural networks are the recent ways for understanding the boundaries and advantages allowing for more efficient modeling and are expected to increase in future in landscape planning and design studies.

A simultaneous removal of nitrate and pesticide endosulfan in ground water using membrane biofilm reactor (H2-MBfR) data is discussed in paper eleven. The biofilm reactor has proved to be efficient for depuration of water contaminated with nitrate and pesticide endosulfan.

In paper twelve, dependence of phytomass on environmental factors from Georgia has been evaluated, indicating that phytomass abundance is affected by different environmental factors in different landscapes, and analysis of phytomass changes on the background of changing environmental factors will prove beneficial.

Evaluating the contributions of internship to landscape architecture education has been discussed in paper thirteen. Authors have proposed that increasing the internship period, development of internship scope/number, establishment of internship place database, supervising internship process, creation of internship training program and effective internship exams will prove helpful in this connection.

Paper fourteen presents the results on the effects of mycorrhizal inoculation on growth and some quality parameters of ornamental plant species cultivated under salt stress. The results have shown that mycorrhizal application of cut flowers grown in greenhouse, positively effects plant growth and some quality parameters by increasing tolerance to salt stress.

In paper fifteen, main problems of sustainable development of the South Caucasus and processes of transformation of landscapes (ecosystems) biodiversity has been evaluated by a group of well-known scholars. They have enlightened the fact that more than twelve landscape types face problems of sustainable development and biodiversity conservation in the South Caucasus.

An influence of the meteorological factors on ecological conditions of the atmosphere in Tbilisi-Georgia has been investigated in paper sixteen with the aim that establishment of anthropogenic aerosols change dynamics in the atmosphere of the city, their 
distribution, concentration, under complex orographic and climate conditions. The meteorological elements have played an important role in the aerosols present in the atmosphere, and a correlation has been noted between the meteorological elements and atmosphere polluting ingredients, main part being contributed by the motor transport with the pollutant concentrations frequently exceeding and promoted by physico-geographical conditions as well as meteorological conditions leading to urban microclimate changes.

Topic investigated in the paper seventeen is modelling of soil erosion in the Chagan river basin of west Kazakhstan using RUSLE and GIS tools because soil erosion is one of the most important agricultural problems in Kazakhstan. The authors have identified that based on the trend of annual loss of soil erodibility in the Chagan River basin, there is a need for preventive and remediation measures in the area. GIS methods have provided accurate definition of spatial distribution of RUSLE parameters. It has also been shown to be a simple and cheap tool for soil erosion modelling, risks for erosion potential and hazardous area difficult to observe on the ground.

In paper eighteen, control of soil erosion measures on mountain slopes of Georgia has been discussed. A method to calculate the erosion intensity has been developed, allowing realization of agrotechnical, hydrotechnical and phytoamelioration measures. The ways of reducing the filtration currents have been studied, thereby presenting the ways to increase the safety of mountain slopes and reduce the negative effect of water erosion processes.

Assessment of the main city square of Aydın, Turkey using urban space quality criteria has been the subject of study in paper twenty. The aim was to evaluate the fact that city squares traditionally shaping the identity of the entire cities are pulsating hearts of the communities as well as most important parts of the open spaces, their quality is not related only to the design of the place but also the image and identity, accessibility, sociability, functionality, activity diversity, and finally the livability, stressing the fact that the city squares should be considered holistically from this perspective in order to improve the urban space quality.

In paper twenty, one of the topic investigated is agricultural crops common in the Chorokhi and Mtkvari Upstream according to the Old Turkish census books, mainly based on the historical sources from Old Turkish Census Books, drafted by Ottoman authorities, such as The Grand and Brief Books, which have been translated into Georgian. The grain-growing has been a leading branch and the major agricultural crops grown were wheat, barley, rye, panic grass, chick-pea, and lentil together with walnut, different fruits and vine varieties. The traditional structure of agriculture in the area has not changed essentially and principal features of specialization have been preserved with such additions as nuts and tea.

Determining of olive cultivars by deep learning and ISSR markers has been discussed in paper twenty-two with the aim of studying accurate estimation of olive varieties by using morphological characters through ISSR Markers.

In paper twenty-three, modelling of microbiological contamination in the Marmara Sea, Bursa-Turkey has been investigated to design and develop the feed forward neural network (FNN) model structures for forecasting faecal coliform concentrations and microbial water quality in the area. The developed model structures have predicted microbial contamination in the coastal environments and provided information on the more effective integrated sea coast management and protection of human health.

A reflection of environmental based agricultural land protection program (Çatak) on farmers implementations has been evaluated in paper twenty-four. Accordingly, the authors production techniques like certified organic farming, controlled use of pests and fertilizers have increased significantly following the application of ÇATAK program. It has proved to be effective in the minimum tillage and stone removing, drainage, gypsum implementation, use of farm manure and drip irrigation have been found to be more effective after the program application.

An ecological based approach for determining suitable landfill from Kilis -Turkey has been the topic investigated in paper twenty-five. The map of suitable landfill sites produced during this study served as an important ecological guide and its necessity for spatial planning has been stressed.

In paper twenty-six, the influence of green areas on city-dwellers perceptions of air pollution has been studied. This case study from Nigde-Turkey has been carried out following the urban development and change, coupled with rapid population growth. The authors have aimed to determine the effect of green areas in order to improve quality of life and create positive perceptions on air quality by modifying physical and social environments within the cities. The paper stresses the fact that the green spaces in convenient numbers, size and quality should be included in city centers for improving the quality of life in the cities.

Paper twenty-seven presents data on the determination of ecotourism potential in national parks with an example from Troy Historical National Park, Çanakkale-Turkey. Even though the villages within this national park have potential for constituting sources for ecotourism in natural and cultural terms, they need to be developed and supported economically and socially in order to serve as contributors to local economy. 
The attitude of hunters on snake habitats and their management system in Cyprus has been investigated in paper twenty-eight. According to the authors most of the hunters know the snake population is decreasing day by day and the biggest threat to them is killing during hunting activities. Due to numerous hunters and excessive hunting on a small island, the snakes of all area are being targeted by the hunters, as avoiding them is impossible which leads to hunting as a major threat.

The results related to assessment of sand dune ecosystems with sea daffodil in Bartin-Turkey are presented in paper twentynine. This study reveals that recreational tourism activities produce adverse effects on Pancratium maritimum and on its habitats. Authors suggest alternative active precautions, like production trials, preparation of dune ecosystem maintenance, ensuring conditions for growing dune species, taking necessary environmental protection precautions, making necessary environmentally-friendly arrangements in highly sensitive areas like Bartın sand dunes.

Paper thirty deals with assessment of the relationship between the surface temperatures and built-up urban environment in Ankara city center. According to the assessments, the local climate zone system should be supported by technical research and field studies and adapted to its use in Turkish cities.

Investigation of aged textiles using scanning electron microscopy is the topic investigated in the pear thirty one. Authors have stressed the fact that monitoring fungal contamination represents the basis for a proper conservation strategy of indoor heritage environments, to diminish their potential role in the degradation of cultural heritage and the people health effects.

In paper thirty two, the optimization of energy consumption for sunflower production using data envelopment analysis approach has been presented. According to these researchers, average yield and energy consumption for sunflower production was $2124.4 \mathrm{~kg} \mathrm{ha}^{-1}$ and $13517.45 \mathrm{MJ} \mathrm{ha}^{-1}$, however, with DEA application, the technical, pure technical and scale efficiencies of farmers a large part of total input energy can be saved while holding the constant level of sunflower yield.

The results related to the examination of Selcuk University Alaaddin Keykubat Campus in the context of ecological landscape design are discussed in the last paper of his special issue. According to the investigators for achieving campus sustainability and sustainable landscape design more effectively there is a need for cooperation and involvement of all stakeholders such as students, faculty and staff, university management, funding agencies, and the community.

Scientists are carious to find how much biodiversity is on our earth. Conservation is needed to preserve it and protect endangered species as well as their habitats. Thinking that variety is the spice of life, biodiversity makes Earth's ecosystems spicy in the real sense. It is a complex yet growing topic of interest not only to scientists, but also to the world policymakers.

This issue provides some specific efforts to counter biodiversity loss. Significant areas of the world are now being conserved as part of protected areas; value of biodiversity for society, our social and economic needs as well as our own health and well-being, are being widely recognized. UN has declared 2011-2020 (CBD 2010c) as the "Decade on Biodiversity", providing a framework upon which they are working with their partners to engage in activities, helping countries to manage biodiversity. All humans on this planet need to work hard to maintain its biodiversity. Thousands of conservation areas have been created with cooperation of local, national, and international organizations in order to preserve the biodiversity of threatened regions.

By 2050, the CBD aims for everyone to live in a world where "biodiversity is valued, conserved, restored and wisely used, maintaining ecosystem services, sustaining a healthy planet and delivering benefits essential for all people", however, there is still much work left to do as enlightened by this special issue.

\section{Guest Editors}

\author{
Professor R. Efe \\ Department of Geography, \\ Balikesir University, \\ Balikesir, 10145,Turkey \\ Email: recepefe@hotmail.com
}

Professor M. Öztürk

Botany Department \& Centre for

Environmental Studies, Ege University,

Bornova-Izmir, 35100, Turkey

Email: munirozturk@gmail.com 